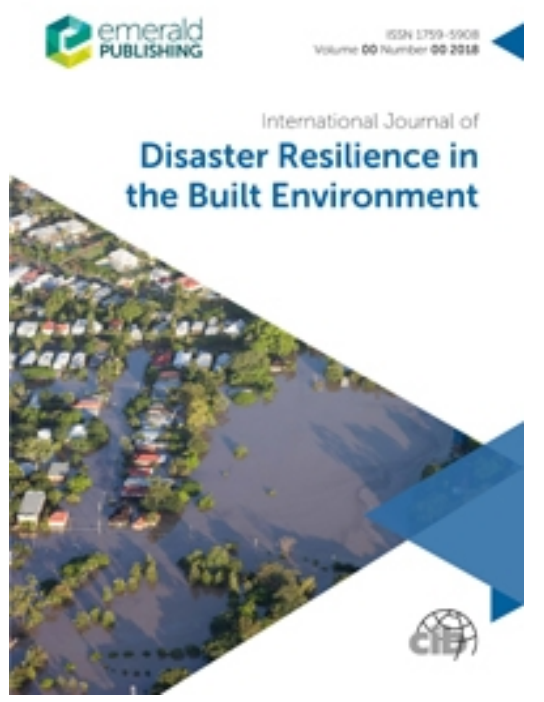

\title{
A Framework for Reconstruction of Road Infrastructure after a Disaster
}

\begin{tabular}{|r|l|}
\hline Journal: & International Journal of Disaster Resilience in the Built Environment \\
\hline Manuscript ID & IJDRBE-03-2017-0018.R2 \\
\hline Manuscript Type: & Research Paper \\
\hline Keywords: & $\begin{array}{l}\text { disaster recovery, post-disaster reconstruction, road maintenance, } \\
\text { framework, road infrastructure, local government }\end{array}$ \\
\hline \multicolumn{2}{|l}{} \\
\hline
\end{tabular}

\section{SCHOLARONE ${ }^{\text {M }}$ \\ Manuscripts}




\section{A Framework for Reconstruction of Road Infrastructure after a Disaster}

\section{Abstracts \\ - Purpose}

This paper identifies the main aspects requiring immediate attention in the postdisaster reconstruction of road infrastructure, thereby providing a major synthesis that advances our understanding in this important area.

- Design/methodology/approach

Literature and empirical evidence obtained from documents and semi-structured interviews with twenty-eight respondents of three case study districts in Aceh, Indonesia was analysed using NVivo 10. The findings were validated through triangulation with the literature and consultation with the experts in the field of disaster management and road infrastructure.

- Findings

The authors propose a framework for the reconstruction of road infrastructure, which respond to the peculiarities of road projects in a post-disaster setting. The framework comprises various components requiring detailed attention in the reconstruction process and describes their position in the road project and disaster management cycle.

- Originality/value

The framework fills the gap in the body of knowledge with regards to road infrastructure reconstruction in a post-disaster context. For the first time, this paper recognises the importance of local government capacity in the Aceh Province with regard to the sustainability of the post-disaster reconstruction assets. 
Keywords: road reconstruction, disaster recovery, post-disaster reconstruction, road maintenance, framework, reconstruction policy

\section{Introduction}

The earthquake and tsunami on the $26^{\text {th }}$ December of 2004 in Aceh, Indonesia, resulted in a great number of fatalities and economic losses. The disaster caused more than 120,000 deaths, affecting more than 1 million people; and caused US\$ 4.4 million worth of damages and losses. Subekti (2009) highlights that as much as US\$ 7.2 billion of pledges were made and more than 900 national organisations from 55 countries were involved in the reconstruction of Aceh.

The reconstruction of disaster-affected areas would generally aim towards implementing the 'build back better' principle. The principle aims at "using the opportunity of a disaster to leave societies improved, not just restored" (Fan, 2013). The extent and scope of the implementation of the 'build back better' principle is primarily determined by the level of damage and the availability of funds for the reconstruction (Pranoto, 2011). In the road sector, this can be translated into building a road network with a better surface, and extending the road network coverage to help stimulate the local socio-economic growth.

However, the reconstruction of road infrastructure in a post-disaster reconstruction setting requires a different approach compared with a project in a normal development context. Disaster recovery projects are seen as having their own unique identity, particularly due to significant stakeholder issues (Baroudi and R. Rapp, 2014, Haigh and Sutton, 2012), resource challenges (Chang et al., 2011, Chang et al., 2010a, Chang et al., 2010b, Chang et al., 2012), capability issues (Crawford et al., 2012) and even long-term reliability concerns (Hayes and Hammons, 2000). Hayat and Amaratunga (2011) suggest that the relatively few aid agencies focusing on the road reconstruction, difficulties in producing the final design, the complicated land acquisition process, conflicting regulations, and high corruption risk are some of the challenges that a project in post- 
disaster setting needs to address whilst also being faced with issues commonly found in road projects in normal development context.

In post-disaster reconstruction, the economic rationale in the decision-making process, and the comprehensive feasibility studies which accompany large infrastructure projects in normal development context may not be applicable due to the pressure to act quickly (Sihombing, 2009). The feasibility studies applicable in a normal development context may need to be adapted and adjusted to meet the postdisaster reconstruction peculiarities. Without which, there is a major concern towards the value of investment and the sustainability of the reconstructed assets.

Consequently, the authors argue that post-disaster road reconstruction requires different approach. An approach that incorporates all the limitations and challenges that exist in a post-disaster context, without swaying too much away from the necessity to consider the overall cost of the project, in particular the long-term needs of maintenance. Within this context, the authors urge the need to establish a framework for the reconstruction of road infrastructure in the post-disaster setting. Such a framework is required to ensure that the various aspects and peculiarities of the postdisaster reconstruction are put into account in the post-disaster reconstruction plan. The framework would help improve the sustainability of the reconstructed asset and maximise the value of investment made in the post-disaster reconstruction.

In this paper, unless documents are publicly available and provided as references, identifying specific organisations and individuals is deliberately avoided. This approach is adopted to avoid undermining organisations and individuals who have put their best efforts in such a challenging circumstance whilst preserving the confidentiality of sources.

\section{Methodology}

The study was carried out in three case study districts in the province of Aceh, Indonesia; the district of Aceh Besar, Aceh Jaya, and Aceh Barat Daya. Replication 
logic (Yin, 2013) was adopted in the selection of the case studies. The limited time and resources available for the study led to the selection of the literal replication approach.

The criteria of the case study districts eligibility were set as the following: the district was directly affected by the 2004 earthquake and tsunami; the district was established prior to the tsunami in 2004; the district had road projects implemented under the posttsunami reconstruction scheme; and the availability of and access to data.

The data was collected primarily from documents, archives and in-depth semistructured interviews. Twenty-eight in-depth semi-structured interviews were conducted with the representatives of the road infrastructure stakeholders at the national, provincial and local level, who were directly involved in the reconstruction of road infrastructure in Aceh. The basic profile and distribution of the interview respondents are presented in Table 1 , and were selected using a combination of purposive sampling and snowballing method.

Content analysis technique was performed with the aid of nVivo 10 software. A screenshot sample of the nVivo coding structure for the road maintenance external factors is shown in Figure 1. The findings of the study were validated through triangulation method by reviewing the literature and consultations with five experts in the subjects of post-disaster reconstruction and road infrastructure management.

Table 1 - Basic Profile of the Respondents at the District Level

\begin{tabular}{|c|c|}
\hline Institution Types & Total \\
\hline Public Works & 9 \\
\hline Consultant & 4 \\
\hline Contractors & 3 \\
\hline Planning Agency & 5 \\
\hline Disaster Management agency & 3 \\
\hline Donor Organisation & 2 \\
\hline Transport agency & 1 \\
\hline Government Office & 1 \\
\hline Total & 28 \\
\hline
\end{tabular}




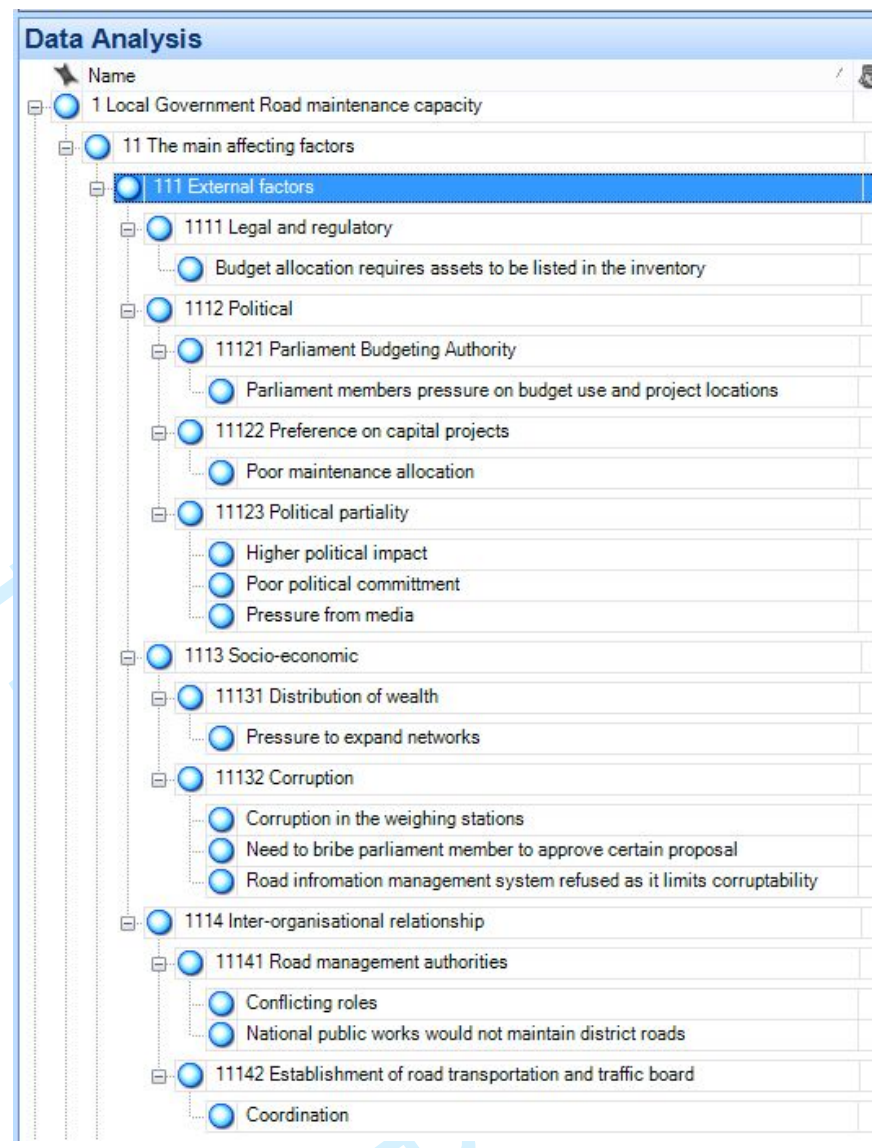

Figure 1 - The coding structure for the external factors in road maintenance capacity

Based on the result of the data analysis, the framework for the post-disaster reconstruction of road infrastructure was formulated, in accordance with the different phase of disaster management and the road project life cycle.

\section{Road Project Life-Cycle and its Position in the Post-Disaster Reconstruction Context}

The life cycle of the road infrastructure project generally consists of procurement; operation and maintenance; as well as renewal or disposal of assets. The procurement phase includes the planning process and comprises a set of feasibility studies to support and justify the needs for the project and its associated costs with regards to economic value (Life Cycle Cost Analysis - LCCA) and environmental impacts (Life Cycle Assessment - LCA).

A generic process of road infrastructure planning and development comprises four phases: feasibility studies; preliminary engineering planning; final engineering 
planning; and construction planning (FTA, 2010). The accompanying LCCA should therefore consider the costs related to initial construction and the following maintenance costs (FHA, 2002).

The development phase is followed by maintenance and upkeep activities to preserve the road to a certain level.

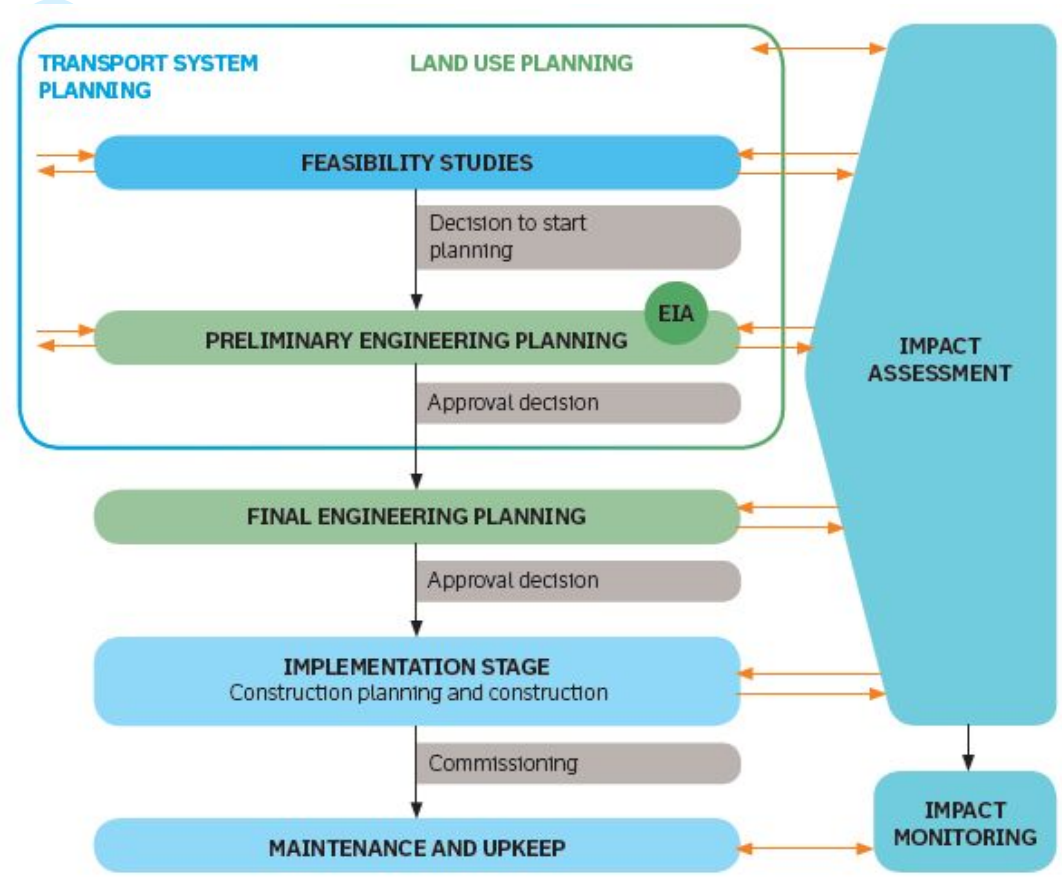

Figure 2 - Road Planning and Development Process (FTA, 2010)

In a post-disaster context, the road project life-cycle spans between two phases of the disaster management cycle, which are_generally coordinated by different institutions. The link between the road project life cycle and the disaster management cycle is illustrated in Figure 3.

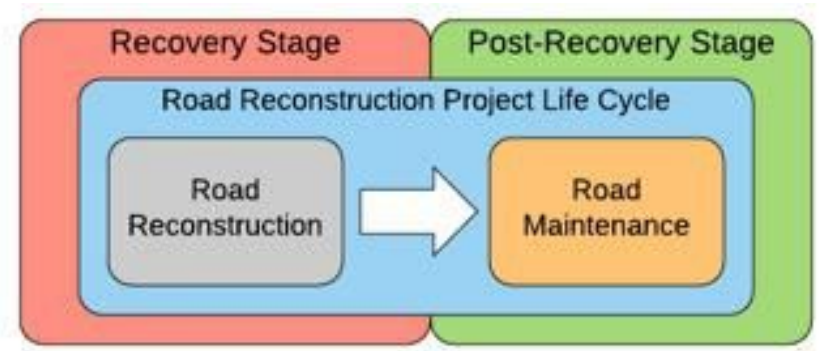


Figure 3 - Relationship between the Road Project Life Cycle and the Disaster Management Cycle

Nevertheless, as previously discussed, it is argued that the comprehensive planning process and feasibility studies required in the normal development project may not be applicable in a post-disaster and emergency, due to the limited resources and the high pressure to accelerate the reconstruction process. The comprehensive feasibility studies may therefore be replaced with a simplified approach, such as the design review concept, which determined only the basic concept, tender documents, and the estimated project value (Sihombing, 2009). In major disaster, such as in Aceh, the reconstruction process was implemented by the National Government (NG), Donor Agencies (DAs) and Non-Government Organisations (NGOs). The long-term responsibility of the road maintenance is accordingly performed by the local governments as the end beneficiaries. Accordingly, the various components of the proposed framework are elaborated in the following sections.

\section{Road Reconstruction Phase}

\subsection{Integration of future maintenance needs in the reconstruction plan}

The findings of the study emphasise the needs to have road maintenance integrated in the reconstruction plan at the earliest time possible. In most countries, investing money in building new roads is more politically favourable than maintaining them (Levik, 2001). Road maintenance works are less attractive to politicians and road engineers when compared with new road construction, road rehabilitation, or social programmes (Donnges et al., 2007, UNESCAP, 2005). This condition is affected by the value of the project, the relatively more sophisticated level of the work, and the immediate impact that a capital project offers (ADB, 2003). In the case study district, the political intervention occurred in the form of shifting the development plan towards certain sectors, as well as in determining road project types and location. Building new 
roads and upgrading road surface was preferable than the road maintenance. As described by PM06:

\section{"Maintenance is not considered a priority. Why? Because there are still many other roads that have not been paved... The budget allocation (needs) for the construction is also not small. So, it is considered that the priority should be there (for the construction)." - PM06}

From the technical aspect, the selection of road surface type and design for the reconstruction may have a long-term impact towards future maintenance needs. In Aceh, Hot Mix Asphalt (HMA) was widely used as the 'new' standard for road pavement in the area. This option appeared to be reasonably justified, as the road deterioration rates are primarily affected by the construction quality; material standard; design specification, proper craftsmanship (Kendrick, 2004), and the age of pavement (Boamah, 2010).

However, it was identified that the wide application of HMA in road projects during the post-disaster reconstruction period changed the way the local road authorities perceive the unique advantages that different road surface types offer. HMA pavement became a development target and was adopted as the new standard for the district roads. HMA's better durability, compared with gravel roads and macadam roads, was also perceived as the quick solution to the road maintenance problem. Consequently, instead of providing regular maintenance to the existing road networks, the gravel roads and macadam roads in the districts were left to deteriorate until there was enough budget to upgrade them to HMA. Respondent CS02 explained:

"So now we are still upgrading roads. What was macadam we upgrade them to Hotmix (HMA). " - CSO2

Ironically, the HMA pavements were also neglected from maintenance as the budget allocation was used to expand and upgrade the 'inferior' road network of gravel and 
macadam types. Respondent CS10 added that new road construction or surface upgrade projects were occasionally disguised as road maintenance projects in order to receive the financial assistance from the NG, which was restricted to maintenance activities:

"In some occasion, we construct new roads, but the (project) title is maintenance.

This was done so that financial aid from the central government can be obtained. So, we got the maintenance fund, but we could not use it (for maintenance). We had to use it for the road construction." - CS10

ADB (2003) refers to this problem as the road agency's poverty trap i.e., building more roads or improving roads to the wrong standards; approving only asphalt road projects even though expensive to build; or failing to recognise that some roads are no longer maintainable and need to wait for reconstruction. Accordingly, as the higher road specification is more expensive to build, more financial resources are potentially wasted due to the lack of maintenance. Unfortunately, learning from the Aceh experience, it seems that NG, as well as DAs who reconstructed and funded the road projects, also fell to what ADB refers to the road agency's poverty trap above. Whilst being reluctant to providing the maintenance needs, arguing that the local governments as the end beneficiaries of the project were expected to allocate these needs from their own budget-

Accordingly, it is argued that the long-term road maintenance needs should be included as an integrated part of the road reconstruction programme, by those who are providing the road infrastructure. The experience of the rural road programme in India, Pradhan Mantri Gram Sadak Yojana (PMGSY), provided a successful example of road development project by including the maintenance needs for a 5-year period in the road rehabilitation contract (Donnges et al., 2007). Such a program provides an opportunity for a gradual transition of maintenance responsibility whilst introducing the road maintenance culture to the local authorities. 
Complementing the above arguments is the need to have regulations and agreements that clearly stipulate the parties responsible for the maintenance of the assets in the future. This issue is related to the asset ownership and asset transfer problem, which will be described in more detail in the later section 7 on the asset transfer.

\subsection{Local government involvement}

In a normal development context, the best possible alternatives of methods and specifications for a project can be determined through LCCA. LCCA is generally carried out by or for the agency who has the most interest to having the lowest cost of ownership throughout the assets' life (Praticò et al., 2011, Cuéllar-Franca and Azapagic, 2014).

However, in a post-disaster reconstruction, parties who are supposed to have the most interest to gain the most economic benefit are rather vague, particularly when parties who pay for the procuring the assets (NG or DAs) are not the one who will own, operate and maintain them in the long run (LGs). Having no obligatory contribution towards the capital investment, LGs are left with no options but to accept these assets, as the largest part of the assets' life cycle cost have been paid for virtually without obligations to repay.

Being an affirmative projects, the assets providers (NG and DAs) therefore need to minimise the potential lost by estimating and building the capacity of the LGs for whom they are transferring the completed assets to, by involving them in the reconstruction process. Local governments' involvement in large infrastructure project has been advocated as one important key to successful and sustainable projects at the subnational level (Kloot and Martin, 2000, ILO, 2003), and in particular within the context of disaster management (Nazeer et al., 2006, Col, 2007, Falato et al., 2007). Nevertheless, devastated local governments condition was a major constraint to the effective and efficient involvement of the local governments in Aceh. As respondent Val04 highlights, understanding the local situation carefully and contextualising the 
problem before applying the textbook answer would be the key to the reconstruction success. The extent to which the local governments can be actively involved in the post-disaster reconstruction is highly determined by the impact of the disaster and the resilience level of the affected local governments.

The "local government involvement" component in the framework accordingly highlights the needs to sufficiently investigate the impact of the disaster and the resilience level of the affected local governments, as well as the various methods that could be used to aspire the involvement and the contribution of the local governments in the reconstruction process.

The study identifies three major ways that the local governments and the local stakeholders could be involved in the reconstruction process: input gathering for the reconstruction plan; the recruitment and secondment of local governments' employees in the reconstruction agencies; and through the coordination and distribution of tasks between the reconstruction agency and the local governments. Not only did such arrangement acted as a form of capacity building, but as respondent PM09 also emphasised, the reconstruction must involve the local personnel as they know the area very well. In turn, this would accelerate the reconstruction process and also stimulate and help create the sense of ownership of the local people towards the reconstruction assets.

\section{Road Maintenance Phase}

The road maintenance phase takes place immediately after the project completion and spans towards the end of the project life-cycle

The internal and external factors affecting the road maintenance capacity are interrelated to each other. Brooks et al. (1989) suggest that improving the institutional arrangement is more difficult than introducing specific management or technical advances. The relationship is presented in a 'pyramidal' model as illustrated in Figure 4.a below. Using Brooks et al. (1989) pyramid as the basis of the model illustrated in 
Figure 4.a, Robinson et al. (1998) propose a set of recommendations for steps in implementing changes in the road management sector (Figure 4.b).

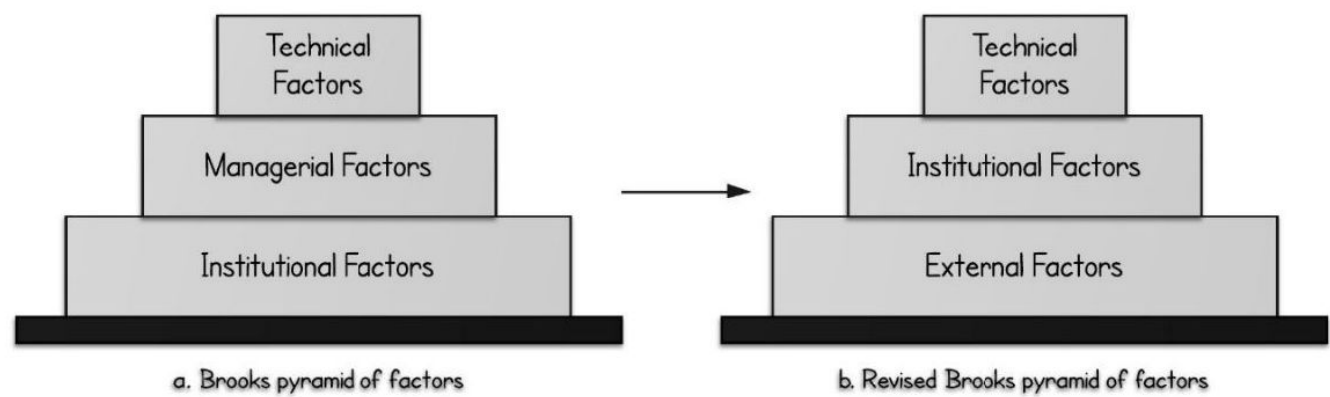

Figure 4 - Brooks Pyramid (Brooks et al., 1989, Robinson et al., 1998)

The recommendations can be summarised as in the following:

- Address the external factors: gaining political commitment, possibly by the involvement of road users and other stakeholders; agreeing upon the restructuring policy and institutional framework; framing any legislation required to support the changes, and securing and maintaining the availability of sufficient funds for the implementation of policy.

- Address the internal institutional factors to improve effectiveness and efficiency.

- Address the technical factors.

Not only does the pyramid model illustrate the need to implement changes from the bottom element to the upper ones, the model also demonstrates that the elements of the lower part act as the enabling elements for the upper ones. Hence, it suggests that promoting changes on the technical aspects may not be effective and efficient if the institutional factors are not sufficiently addressed. Accordingly, modifying the institutional arrangement may not be productive if the support required from the external institutions (i.e. political commitment and the regulatory framework) is not adequately obtained. 


\subsection{The external factors}

The external factors of the road maintenance capacity are those that are outside the direct control of the road authorities, and may somehow constrain the way in which they operate. These factors are essential in enabling a supporting work environment for the local governments in performing the road maintenance tasks. The external factors include environmental; legal and regulatory arrangements; political; socioeconomic; and inter-organisational relationship.

The environmental conditions such as flood, landslide and other weather conditions negatively affect the deterioration rate of the road infrastructure. Changes in the temperature and cracks on the surface of the pavement would result in water ingress and disintegrate the road (Benedetto and Pensa, 2007, Chinowsky et al., 2015).

The legal and regulatory aspect of the road maintenance capacity covers laws and regulation that provide the legal basis for the road authority to carry out their activities. This may include laws and regulation regarding the organisational structure and interorganisational relationship between authorities involved in the road maintenance, as well as the financial and budgeting procedure.

The study findings indicate that political pressure appears to be highly influential in the decision-making process. The parliament budget authority, designed as a means to demonstrate and incorporate the community's aspiration in the development program, eventually affected the development planning. As a result, the annual budget proposal of the local governments did not necessarily reflect and represent the development plan, which was produced by the planners, but was rather filled with aspirations and demands from the politicians, which may or may not be in accordance with the development plan. Respondent CS02 described:

"When we make the (budget) proposal, we have to see that election zone 1 (for example) has been allocated Rp 5 billion, election zone 2 also need a certain 
sum. We need to secure this and not to miss any single election zone. Otherwise, the proposal will be jumbled (by the parliament). So it is a must." - CSO2

Additionally, from the socio-economic perspective, the study identifies that the pressure from the community to disperse road projects in different locations as a means of distribution of wealth is one of the external factors that needs to be addressed. Such pressure results in road authorities undermining the importance and the economic benefit of maintaining the road infrastructure, particularly when it needs to compete with new road projects.

From the inter-organisational relationship perspective, a clear division of tasks and responsibilities between various institutions involved in the management and maintenance of road infrastructure and traffic is essential. It was identified that the public works and the transportation agency were trapped in a 'blaming circle' with regards to the rapid deterioration of the road infrastructure. The public works accused that it was due to the transportation agency's poor performance in monitoring and controlling the overloading traffic. On the other hand, the transportation agency blamed the public works for building roads with poor quality in the first place (Hayat et al., 2015). Respondent Val04 and Respondent Val05 further added that the 'blaming culture' between government institutions involved in the road management may be affected by the lack of training and assessment to properly estimate the traffic. However, Val02 argued that this problem was actually rooted in the fact that the axle load limit had been set to a very low level, which was, "below the reasonable economic level for the operational of most of the networks." As a result, there had been too much incentive for the operator to break the axle load limitation. This condition was exacerbated by the very low capability of the transportation agency to control the limit and the high level of corruption and abuse of any control system by both the operator and the community (Hayat and Amaratunga, 2014). 


\subsection{The institutional factors}

Following Robinson et al. (1998) approach of classifying road maintenance issues, the institutional factors include: financial management; human resource; and organisational management.

The global experience proves that when budget allocation for road maintenance has to compete with other sectors, the road maintenance normally loses in priority, despite the suggestion that adequate maintenance should have the highest priority on the resource utilisation. It is argued that such a condition occurs since the benefits of maintaining roads have not been widely understood by the decision-makers, and that the consequences of inadequate maintenance is not always immediately obvious (Potter, 1997). In other words, it is hard to convince the politician to secure funding and to allocate funds to repair roads that do not seem to be broken (ADB, 2003), regardless of the fact that billions of the capital investment made in the road sectors will diminish due to maintenance neglect, as experienced in the Sub-Saharan Africa region (Heggie, 1994). With regards to this particular issue, Respondent CS09 confirmed:

"For the maintenance (allocation), it is not certain. It seems that there is no maintenance this year, not at all. So, it is focused on road upgrade and new construction." - CSO9

On the other hand, the findings also indicated that human resource capacity as one of the most important factors affecting the capacity of the local government in road maintenance. Nevertheless, soft projects such as training and capacity building programs appeared to get little awareness and interest from the parliament. Accordingly, the budget proposal for training was rarely approved. Respondent CS10 explained that the parliament was more concern on activities, which could give the direct and immediate result. He described: 
"In addition to the budget (limitation), there is also an issue of awareness. The awareness of our parliament is rather poor towards such soft projects. Why would we spend money if it is only for training? The results are not immediately visible. For instance, if we spend the budget allocation of Rp 500 million, if it used for constructing road we would get 500 meters. The results are immediately visible. - CS10

In accordance with the aforementioned issues, Mwaipungu and Allopi (2014) emphasises that a maintenance management system needs to be developed to determine the optimum maintenance frequency and lead to reduced total vehicle operating and maintenance cost. Accordingly, PM01 strongly suggested that the local governments need to develop a reliable road management system that can be used to justify the needs to perform maintenance works, as well as the consequences of not performing the maintenance. By adopting a proper road information system, the local governments would be able to produce a reliable justification for the road maintenance budget proposal. The system would also be able to provide the parliament with informed consent options regarding the consequences of selecting one of the maintenance plans over the others.

From the organisational and management aspect, learning from the experience of the Sub-Saharan African countries, the institutional problems in the road maintenance were rooted to the poor management and the lack of enabling environment within the road agency, which undermined the need to provide incentives and to increase staff motivation (Heggie, 1994). World Bank, cited in Klockow and Hofer (1991), adds that the main issues in the road maintenance problems are caused by misallocated fund, unsound maintenance strategies, inefficient implementation and lack of public pressure for better roads. These problems were also identified in the case studies, as respondent CS13 argued: 
"The Local Governments do not optimally allocate maintenance fund for their district unless the roads are located in the centre of government activities. Why? For them, what is important is that the road to the government centre is good. Meanwhile, what we think most important is the economic access, access to the centre of economic activities" - CS13

\subsection{The technical factors}

From the technical perspective, three elements are highlighted to be considered in the post-disaster reconstruction of road infrastructure: road design; traffic loading control; and also plant and equipment to perform the maintenance activities.

The study identifies that selecting and designing appropriate road design is a key for the sustainability of the reconstructed road assets. The road authorities need to have the required knowledge and skills to build and maintain the particular road types as well as to identify the various advantages and disadvantages of each road type.

Furthermore, the road infrastructure is structurally designed to cope with a certain vehicle axle loading capacity. In Indonesia, the standard vehicle maximum axle loading capacity range from 10 tons (class I road) to 8 ton (class III roads) (Law, 2009 no 22). The west coast area of Aceh Province where the case study districts are located is mainly occupied by palm oil agricultural industry and the mining industry. Respondent CS12 explained:

"The roads which are designed for normal traffic are later on used for trucks transporting palm trees. The damaging factor is different, right?... This means that on the one hand the government is faced with the dilemma that if it (traffic loading control) is enforced, they (business investment) may not come to the area. If they are allowed, the infrastructure will be damaged." - CS12

Respondent CS12 also added that in reality the local governments tend to ignore this problem, and are more focused on the direct income that the industry may provide to 
the district. To solve this issue, CS12 later emphasised that the local governments should be in charge and lead the traffic control enforcement. This is particularly due to the involvement of several institutions in the road management.

Accordingly, the proposed framework highlights the importance of traffic loading control facilities to be included in the road reconstruction plan. In Aceh, the earthquake and tsunami destroyed the traffic loading control facilities, leaving only two weighing stations operational until 2014 (Dirjenhubdat, 2014). The reconstruction of road infrastructure needs to ensure that the required plants and equipment to perform the road maintenance activities are available when they are needed, along with the technical capacity to operate and maintain these facilities. The study identified no significant issues related to the technical capacity to operate the heavy machineries and to carry out the required road maintenance works. However, it was identified that the road authority in Aceh Besar lacked the capacity to operate and maintain the laboratory equipment provided for the agency in the disaster reconstruction period by the rehabilitation and reconstruction agency for Aceh and Nias, BRR. Respondent CS02 explained:

"There were donations from the BRR for laboratory equipment, even though they were not so many that we still had to purchase some more. But... until now they have not been optimised as there is no personnel with adequate expertise to manage it." - CSO2

\section{The Transitional Phase - The Asset Transfer Process}

As the road assets were reconstructed by agencies different to those that are responsible for the maintenance, the reconstructed assets were transferred back to the relevant government institutions. The process took place in between the road reconstruction and the maintenance process.

In the post-tsunami reconstruction in Aceh, the delays in transferring the reconstruction assets back to the local governments resulted in maintenance neglect 
of the assets. The absence of clear regulations and prior agreement regarding maintenance responsibilities during the asset transfer process caused disputes to arise between the NG and the local governments. Respondent PM01 suggests that asset valuation method was one of the root problems, as he said

\begin{abstract}
"When we were finished, the most difficult and time-consuming (process) was the asset transfer. The transfer of asset to local governments was difficult. The local governments wanted that the assets to be revaluated, before they would accept them. If they asked for revaluation, they would not sign the value which they did not think represent the current value at that time." - PM01
\end{abstract}

The rigidity in applying the law and regulations for the normal condition in the postdisaster context proved to have caused delays in the asset transfer process. In Aceh, the reconstructed assets had to be listed as the BRR assets before they were transferred back to the local governments after the completion. Accordingly, a definite set of rules and regulatory arrangement was required and need to be agreed prior to the reconstruction or even prior to the occurrence of a disaster. This is particularly because discussing such an arrangement during the post-disaster reconstruction period could be too late, as the focus would be placed on meeting the needs of the affected people in a speedy manner.

Nevertheless, such complication and disputes could be avoided if the changes of assets ownership are not required in the reconstruction process. In the case where it is unavoidable, the "asset transfer" component in the proposed framework accordingly highlights the main concerns that can occur in the asset transfer process. These include the need to have pre-established regulations and agreements regarding the asset transfer conditions and the asset valuation methods. The framework also stresses the need to transfer the assets back to the relevant governments immediately after the project completion. Such an action is required in order to avoid disputes arising from unclear ownership status and maintenance responsibility for the period of 
time between the project completion and asset transfer. Other factors in the asset transfer process include the asset management capacity of the local governments and personnel involved in the post-disaster reconstruction activities; project administration and documentation required for the asset transfer process; and the land registration issue resulting from the land acquisition process. These factors contributed to the delay in the asset transfer process in Aceh and aggravated the road maintenance problems.

\section{Complementing components}

In addition to components requiring particular attentions throughout the project lifecycle mentioned above, there are complementing components to be performed alongside the road reconstruction process. The case study findings suggest that these components, although external to the road reconstruction project, need to be addressed appropriately in the reconstruction process. The absence of which have been identified as detrimental to the overall success of the road reconstruction project. These components are safety and security, and the capacity-building programme to the local governments.

\subsection{Safety and Security}

The safety and security conditions are crucial requirements for the road authorities to implement any projects in the disaster-affected area, particularly in a post-conflict area like Aceh. The "safety and security" component in the proposed framework illustrates the need to continuously assess the safety and security condition, analyse the risks and the potential impacts to the project implementation.

Accordingly, the safety and security component spans across the entire road project life cycle and, therefore, needs to be considered throughout the reconstruction, asset transfer, and the road maintenance phases. The reconstruction plan needs to put into account the access to project sites, the responses and attitude of the indigenous 
community towards the project, and how these factors would affect the implementation of the road projects.

As experienced in the case study district, safety and security threats may come from the communities or individuals living nearby the project sites and from the project contractors. As CS07 added, the project contractors frequently force relaxed supervision and that being too strict in enforcing the construction specification might expose themselves to serious threats as he emphasised:

\section{"For me personally, what is important is that I am safe." - CSO7}

Safety and security threats were also posed by the contractors to the procurement committee. Sihombing (2009) highlights a case where a national company lost a procurement tender due to the local partners' lack of experience in the procurement of heavy vehicle equipment and forcefully tried to justify their bid position. Consequently, in order to avoid threats from the bid participants who were eager to win, the procurement committee had to literally work out of the public reach by working in another city.

\subsection{Capacity Building}

Similar to the "safety and security", the "capacity building" component also spans across the entire road project life-cycle and demonstrates the need to continually incorporate the capacity building programs throughout the entire project life cycle. Kenny (2007) suggests that capacity-building activities are aimed at 'developing the skills, resources and knowledge of groups, organisation or nations.' Hence, practically, capacity building refers to approaches, strategies, and methodologies used to improve the performance of individuals, communities, organisations, or countries to execute particular functions (Kenny, 2007), at the different social levels (Bolger, 2000).

The study identifies the need to adequately design capacity-building programs that address the actual capacity gap. The respondents in all three case studies also 
suggested that the existing capacity building programs were either poorly designed or insufficient for the personnel's needs. For instance, the provision of two or three -day short courses was argued to be ineffective for complicated subjects such as road and bridge design. As a result, it was emphasised that the personnel mostly learnt from the informal interactions with the more senior personnel. The respondents also suggested that the lack of capacity building programs in the districts forced the local personnel to look for assistance from external sources.

\section{The Framework}

This paper proposes a framework, which is developed based on the literature review and analysis of the data. The framework, as illustrated in Figure 5, comprises various aspects requiring detailed attentions and describes their position in the road project and disaster management cycle. 


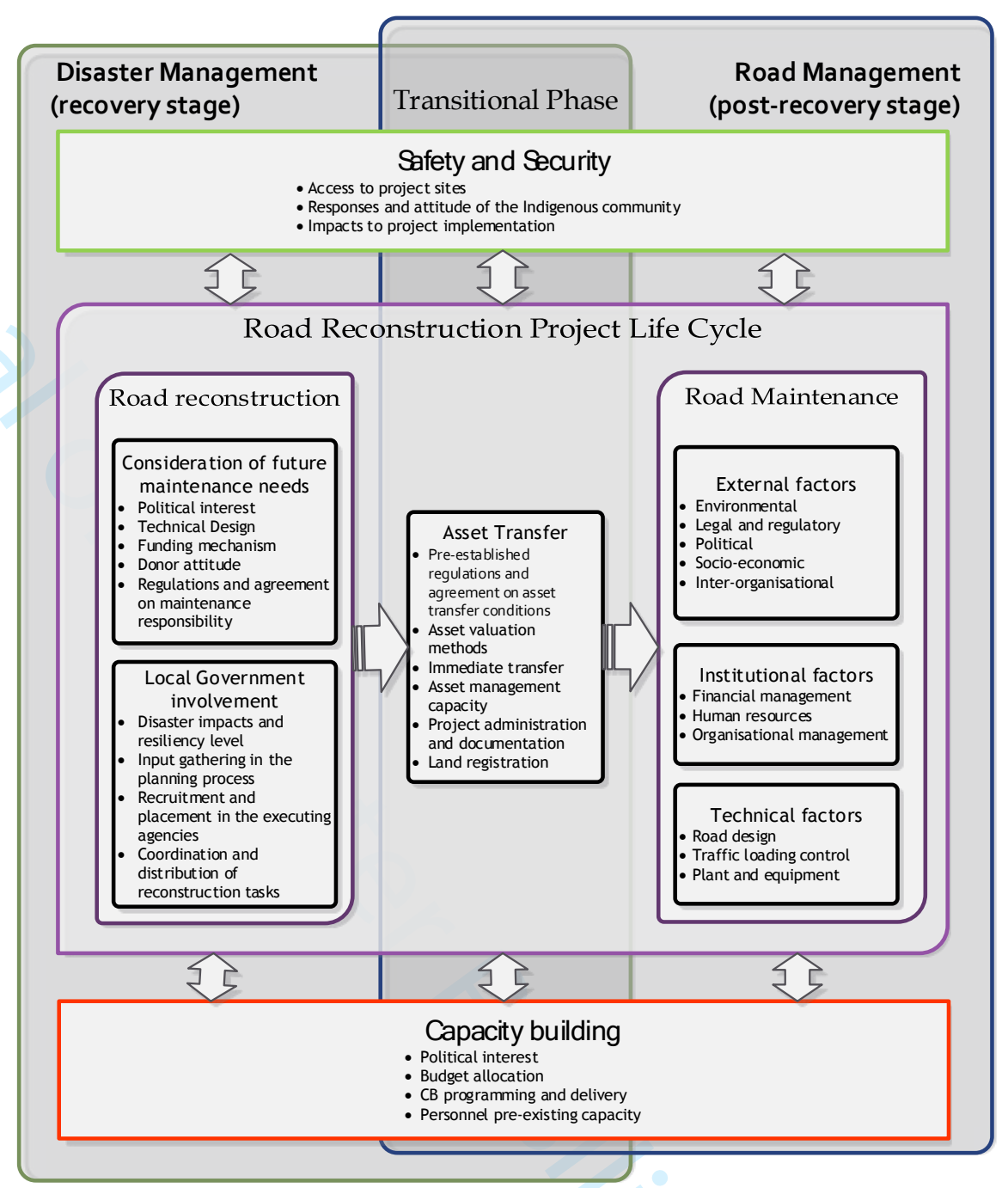

Figure 5 - Post Disaster Road Reconstruction Conceptual Framework

The framework also suggests the incorporation of two main bodies of knowledge: disaster management and road management. The road reconstruction process, which takes place in the recovery stage, highlights the need to consider the future road maintenance needs and the involvement of the local governments in the reconstruction process. The road maintenance aspect, on the other hand, highlights the factors affecting the capacity of the local government in maintaining the road assets. Accordingly, the following sections will elaborate the different aspects of the proposed framework. 


\section{Conclusion}

This paper, for the first time, proposes a framework for the reconstruction of road infrastructure in a post-disaster setting, as detailed in Figure 5, which urges the need to identify and incorporate the various important components of road reconstruction and maintenance at the earliest phase of the reconstruction process, in order to ensure the sustainability of the reconstructed assets. Within the reconstruction process, the framework highlights the importance to consider the future road maintenance needs, which could be affected by political interest, road technical design, project funding mechanism and Donor Agencies' attitude towards the provision of fund for maintenance as an integrated reconstruction scheme, as well as the importance of regulatory arrangement with regards to road maintenance responsibility.

The framework also details and encourages the involvement of the local governments in the reconstruction process, despite their variable institutional capacities. This is one of the most important unknowns associated with the sustainability of the road reconstruction process beyond the responsibilities of constructing the infrastructure. This could be done through input gathering; recruitment and placement of personnel in the reconstruction agency; and through promoting good coordination and distribution of reconstruction tasks. From the road maintenance aspect, the framework identifies the external, institutional, and technical factors that affect the capacity of the local governments in road maintenance, which range from the environmental condition to the availability of plant and equipment. The asset transfer process, which links the two phases of the road project life cycle, highlights the need to have pre-established regulations and agreement on asset transfer conditions and asset valuation methods, and urges the need for immediate transfer of assets upon their completion. These aforementioned elements of the framework need to also consider the impacts of safety and security threats towards the project implementation and to ensure that the capacity building program is set as a continuous agenda that is appropriately designed and sufficiently funded. 
Nevertheless, this paper also invites a discussion concerning the application of the framework. This paper also acknowledges that the various elements listed in the framework are not exhaustive, nor they are mutually exclusive to one another. However, it is through adopting such a framework and testing out the applicability of the various elements, that the reconstruction of road infrastructure in a post-disaster setting could yield the most benefit from the investment made in the reconstruction process.

\section{Acknowledgement}

The authors gratefully acknowledge the financial support provided by the Government of Aceh Province, Indonesia, which made the study possible.

\section{References}

ADB 2003. Road Funds and Road Maintenance: An Asian Perspective, Manila, Asian Development Bank.

BAROUDI, B. \& R. RAPP, R. 2014. Stakeholder management in disaster restoration projects. International Journal of Disaster Resilience in the Built Environment, 5, 182-193.

BENEDETTO, A. \& PENSA, S. 2007. Indirect diagnosis of pavement structural damages using surface GPR reflection techniques. Journal of Applied Geophysics, 62, 107-123.

BOAMAH, P. A. 2010. Development Of Models For Optimal Road Maintenance Fund Allocation - A Case Of Ghana. PhD, University of Birmingham.

BOLGER, J. 2000. Capacity development: why, what and how. Capacity Development Occasional Series, $1,1-8$.

BROOKS, D. M., ROBINSON, R. \& O'SULLIVAN, K. P. 1989. Priorities In Improving Road Maintenance Overseas: A Check-List For Project Assessment. 86, 1129-1141.

CHANG, Y., WILKINSON, S., POTANGAROA, R. \& SEVILLE, E. 2010a. Interpreting Resourcing Bottlenecks Of Post-Wenchuan Earthquake Reconstruction In China. International Journal of Strategic Property Management, 14, 314-331.

CHANG, Y., WILKINSON, S., POTANGAROA, R. \& SEVILLE, E. 2011. Donor-driven resource procurement for post-disaster reconstruction: Constraints and actions. Habitat International, 35, 199-205.

CHANG, Y., WILKINSON, S., SEVILLE, E. \& POTANGAROA, R. 2010b. Resourcing for a resilient postdisaster reconstruction environment. International Journal of Disaster Resilience in the Built Environment, 1, 65-83.

CHANG, Y., WILKINSON, S., SEVILLE, E. \& POTANGAROA, R. 2012. Changes in resource need for postdisaster reconstruction: a longitudinal study in China. Building Research \& Information, 40, 327-336.

CHINOWSKY, P. S., SCHWEIKERT, A. E., STRZEPEK, N. L. \& STRZEPEK, K. 2015. Infrastructure and climate change: a study of impacts and adaptations in Malawi, Mozambique, and Zambia. Climatic Change, 130, 49-62.

COL, J.-M. 2007. Managing Disasters: The Role of Local Government. Public Administration Review, 67, 114-124.

CRAWFORD, L., LANGSTON, C. \& BAJRACHARYA, B. 2012. Building capability for disaster resilience. 
CUÉLLAR-FRANCA, R. M. \& AZAPAGIC, A. 2014. Life cycle cost analysis of the UK housing stock. The International Journal of Life Cycle Assessment, 19, 174-193.

DIRJENHUBDAT. 2014. Daftar Jembatan Timbang Nanggroe Aceh Darussalam [Online]. Available: http://simlalin-hubdat.web.id/jemtim/data/detail/14 [Accessed November 3rd 2013].

DONNGES, C., EDMONDS, G. \& JOHANNESSEN, B. 2007. Rural road maintenance: Sustaining the benefits of improved access, Bangkok: International Labour Office.

FALATO, C. P., SMITH, S. M. \& KRESS, T. 2007. Local government involvement in disaster preparedness in the USA. International Journal of Emergency Management, 4, 575-583.

FAN, L. J. O. H. W. G. H. W. O. O. U. S. O. O. U. F. O. A. P.-O.-F. P. 2013. Disaster as opportunity? Building back better in Aceh, Myanmar and Haiti.

FTA 2010. Road Planning Process. Finnish Transport Agency.

HAIGH, R. \& SUTTON, R. 2012. Strategies for the effective engagement of multi-national construction enterprises in post-disaster building and infrastructure projects. International Journal of Disaster Resilience in the Built Environment, 3, 270-282.

HAYAT, E. \& AMARATUNGA, D. 2011. Road Reconstruction in Post - Disaster Recovery; Challenges and Obstacles. In: AMARATUNGA, D., HAIGH, R., KERAMINIYAGE, K., KULATUNGA, U. \& PATHIRAGE, C. (eds.) International Conference on Building Resilience: Interdisciplinary approaches to disaster risk reduction, and the development of sustainable communities and cities. Kandalama, Sri Lanka.

HAYAT, E. \& AMARATUNGA, D. 2014. The Impact of the Local Political and Socio-Economic Condition to the Capacity of the Local Governments in the Maintenance of Post-Disaster Road Infrastructure Reconstruction Assets. 4th International Conference on Building Resilience. Salford, UK.

hAYAT, E., AMARATUNGA, D. \& HAIGH, R. 2015. Traffic Control Enforcement - The Problems and Dilemma in Maintaining Post-Disaster Road Infrastructure Assets, A Case Study From Aceh, Indonesia. The 3rd PlanoCosmo Conference. Bandung, Indonesia.

HAYES, P. E. \& HAMMONS, A. Disaster recovery project management. Petroleum and Chemical Industry Conference, 2000. Record of Conference Papers. Industry Applications Society 47th Annual, 2000. IEEE, 55-63.

HEGGIE, I. G. 1994. Commercializing Africa's Roads - Transforming the Role of the Public Sector. Environmentally Sustainable Development Division, Africa Technical Department, the World Bank.

ILO 2003. Building Local Government Capacity for Rural Infrastructure Works.

KENDRICK, P. S. 2004. Roadwork: Theory And Practice, Elsevier Butterworth-Heinemann.

KENNY, S. 2007. Reconstruction in Aceh: Building whose capacity? Community development journal, 42, 206.

KLOCKOW, S. \& HOFER, W. 1991. Improvement of road maintenance practices in developing countries: case study from Nepal. Transportation Research Part A: General, 25, 113-120.

KLOOT, L. \& MARTIN, J. 2000. Strategic performance management: A balanced approach to performance management issues in local government. Management Accounting Research, 11, 231-251.

LAW 2009. Lalu Lintas dan Angkutan Jalan. 22/2009.

LEVIK, K. How to sell the message "Road maintenance is necessary" to decision makers. First Road Transportation Technology Transfer Conference in Africa, 2001.

MWAIPUNGU, R. R. \& ALLOPI, D. 2014. THe review of sub-sahara africa gravel roads maintenance management system's monitoring and need assessment: Tanzania experience. International Journal of Sustainable Development and Planning, 9, 74-89.

NAZEER, A., MASOOD, Z. \& SUNGI DEVELOPMENT FOUNDATION. 2006. The role of local government in disaster management : dialogue with the community and local government representatives : analysis \& policy recommendations, Islamabad, Publication Unit, Sungi Development Foundation. 
POTTER, B. 1997. Dedicated road Funds: A preliminary review by IMF. PPAA/97/7, junio.

PRANOTO, S. 2011. Pembelajaran Rehab Rekon Pasca Gempa di Sumatra Barat, Tim Pendukung Teknis Rehabilitasi dan Rekonstruksi, Badan Nasional Penanggulangan Bencana.

PRATICÒ, F., SARIDE, S. \& PUPPALA, A. 2011. Comprehensive life-cycle cost analysis for selection of stabilization alternatives for better performance of low-volume roads. Transportation Research Record: Journal of the Transportation Research Board, 120-129.

ROBINSON, R., DANIELSON, U. \& SNAITH, M. 1998. Road maintenance management: concepts and systems, Macmillan.

SIHOMBING, B. S. 2009. Infrastructure - Stimulating the Triggering Sector, BRR NAD -NIAS.

SUBEKTI, A. 2009. FINANCE: The Seven Keys to Effective Aid Management.

UNESCAP 2005. Road Maintenance Funds, Thailand, UNESCAP.

YIN, R. K. 2013. Case Study Research: Design and Methods, SAGE Publications. 
Figure 1 - The coding structure for the external factors in road maintenance capacity

$87 \times 115 \mathrm{~mm}(72 \times 72 \mathrm{DPI})$ 
Figure 2 - Road Planning and Development Process (FTA, 2010)

$104 \times 82 \mathrm{~mm}(72 \times 72 \mathrm{DPI})$

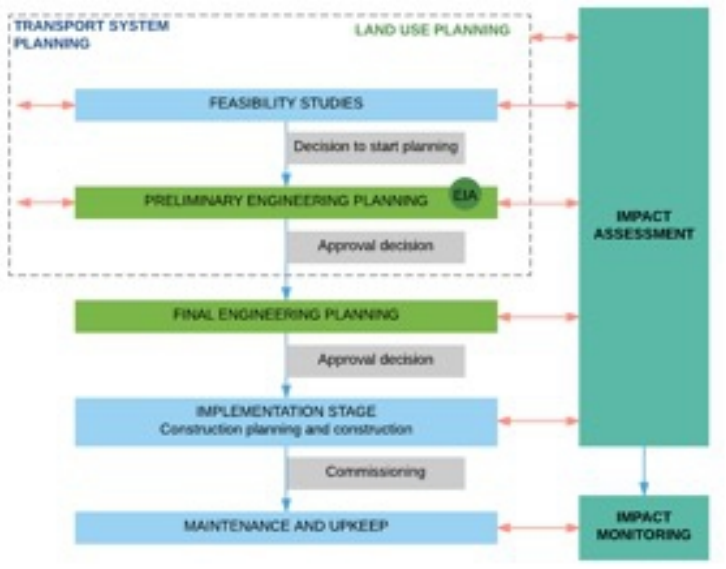




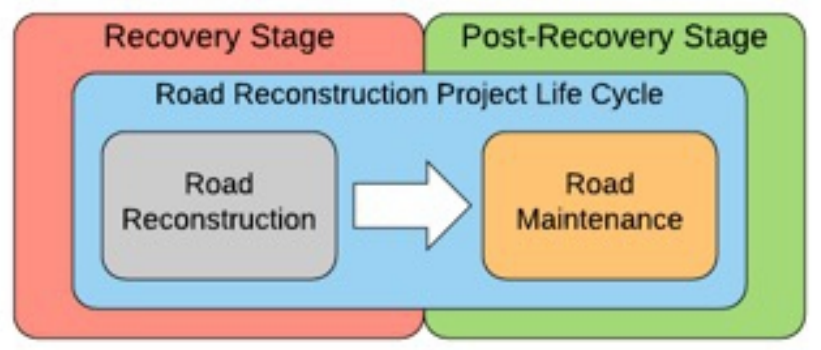

Figure 3 - Relationship between the Road Project Life Cycle and the Disaster Management Cycle $117 \times 48 \mathrm{~mm}(72 \times 72 \mathrm{DPI})$ 
Figure 4 - Brooks Pyramid (Brooks et al., 1989, Robinson et al., 1998)

$127 \times 39 \mathrm{~mm}(72 \times 72 \mathrm{DPI})$ 
Figure 5 - Post Disaster Road Reconstruction Conceptual Framework 